\title{
Equipes virtuais - um estudo de caso na indústria têxtil norte-americana
}

\author{
Viviane Carvalho Bejarano \\ Luiz Alberto Pilatti \\ Luciano ScAndelari \\ Antonella Carvalho de Oliveira \\ Universidade Tecnológica Federal do Paraná
}

\begin{abstract}
Resumo
Com os avanços da tecnologia e da comunicação eletrônica, novas equipes estão se desenvolvendo: são as equipes virtuais, ou grupos formados por pessoas com um objetivo comum que desenvolvem trabalho interdependente primariamente por meios eletrônicos. Apesar do potencial de expansão de negócios e flexibilidade que estas equipes trazem para empresas e funcionários, estruturá-las traz novos desafios para a gestão empresarial. Este estudo analisa as variáveis que podem interferir na implementação destas equipes, a partir da experiência de uma equipe virtual estruturada para operar um centro de distribuição têxtil. Os instrumentos de pesquisa foram: observação participante, análise documental e questionários com os membros da equipe virtual. Os resultados sugerem que, nos relacionamentos intermediados por tecnologia, problemas de comunicação podem ser maximizados, comprometendo a eficácia das interações e da equipe. A equipe estudada não conseguiu superar alguns dos obstáculos comuns às equipes virtuais, o que pode ter contribuído para o insucesso do projeto.
\end{abstract}

\section{Palavras-chave}

Equipes virtuais; CSCW e groupware; Tecnologias de informação e comunicação.

\section{Virtual teams - a case study in an u.s. textile company}

\begin{abstract}
With the advances in technology and electronic communication, new work teams are developing: they are the virtual teams, or work groups formed by people who develop interdependent work using primarily electronic communication. Even though virtual teams offer chances of expansion and flexibility for companies and employees, to properly structure these teams is a new challenge for companies' management. This study analyzes the variables that can intervene in the implementation of virtual teams, through the case of a virtual team structured to operate a textile distribution center. Research instruments used for data collection: participant observation, documental analysis and questionnaires with members of the virtual team. Results suggest that when relationships are intermediated by technology, communication problems can be maximized, compromising the effectiveness of interactions and the team. The studied team did not overcome some of the obstacles common to virtual teams, which may have contributed to the failure of the project.
\end{abstract}

\section{Key words}

Virtual teams; CSCW and groupware; Information and communication technologies. 


\section{INTRODUC̣ÃO}

Num passado ainda recente, o trabalho em equipe desenvolvido em empresas envolvia primariamente interações presenciais na forma de reuniões e trabalho executado em conjunto. Com os progressos tecnológicos dos últimos anos, a maior parte das equipes de trabalho tem incorporado ao seu dia-a-dia pelo menos alguns elementos da interação virtual, envolvendo comunicação nãopresencial intermediada por $e$-mail, telefone, videoconferência, etc., e é crescente o número de equipes compostas por pessoas que se comunicam quase que exclusivamente por meios eletrônicos: as equipes virtuais.

Equipes virtuais oferecem oportunidades ilimitadas de expansão de negócios - com membros de equipes trabalhando em regiões geográficas dispersas é possível ter uma empresa funcionando 24 horas por dia. Num exemplo citado por Polzer (2004), um membro de uma equipe virtual na Alemanha envia o seu trabalho do dia para um colega na costa oeste dos Estados Unidos. Devido à diferença de fuso horário, o colega americano começa o dia com o trabalho que o europeu desenvolveu, eventualmente enviando o resultado do seu trabalho diário a outro colega na Austrália. Com essa dinâmica, o tempo de desenvolvimento de um produto na empresa citada pode ser reduzido a $1 / 3$ do tempo que seria normal se o processo acontecesse num único local.

Estabelecer equipes de trabalho efetivas é um desafio contínuo para o gestor moderno, já que algumas pessoas preferem abertamente o trabalho individual e são relutantes em aceitar fazer parte de equipes (KATZENBACH; SMITH, 2001). Equipes virtuais têm também seus desafios específicos e algumas dinâmicas que naturalmente diferem das encontradas em equipes presenciais.

O objetivo deste artigo é analisar os potenciais desafios na implementação de equipes virtuais efetivas, utilizando como unidade de estudo o caso de uma equipe virtual estruturada para operar um centro de distribuição têxtil nos Estados Unidos. O artigo também apresenta brevemente os conceitos de equipes e equipes virtuais, as tecnologias que possibilitam a existência das mesmas e os comportamentos/hábitos recomendados por estudiosos do tema para que as equipes virtuais maximizem seu potencial.

A pesquisa classifica-se como: indutiva em função do método, qualitativa em função do objetivo proposto e como um estudo de caso em função dos procedimentos técnicos adotados.

\section{O QUE É UMA EQUIPE VIRTUAL?}

Implícito no objetivo deste trabalho - que é delinear os potenciais desafios na implementação de equipes vir- tuais efetivas - está o entendimento de que todos sabem o que é uma equipe. Entretanto, como nota Drucker (2001), a expressão "formação de equipes" tornou-se um clichê bastante comum nas empresas, o que não quer dizer necessariamente que se tenha uma clara visão do que seja formar uma equipe, ou mesmo do que seja uma equipe. Moscovici (1998) também ressalta que, embora o emprego do termo "equipe" seja bastante comum, a ocorrência de verdadeiras equipes é rara. Assim, faz-se necessária uma breve introdução do termo.

Etimologicamente, a palavra equipe se origina do francês équipe, que é um conjunto ou grupo de pessoas que se aplicam à realização de uma mesma tarefa ou trabalho. Katzenbach e Smith (2001) desenvolveram a definição usada como referência pela quase totalidade dos trabalhos sobre o tema: uma equipe é um grupo de pessoas com aptidões complementares, comprometidas com um objetivo comum, que realizam trabalho interdependente e são coletivamente responsáveis pelos resultados. É necessário, para o ótimo entendimento do que é uma equipe, fazer a diferenciação entre uma equipe e um grupo de trabalho: grupos de trabalho são aqueles nos quais os membros apenas dividem informações e melhores práticas ou perspectivas e tomam decisões para ajudar cada indivíduo a melhor desenvolver tarefas na área de sua responsabilidade (KATZENBACH; SMITH, 2001). Ou seja, num grupo de trabalho, não existe responsabilidade coletiva sobre um trabalho ou produto final comum, e muitas vezes o trabalho executado não é interdependente - a cooperação, apesar de ser extremamente importante nas equipes, não "faz" uma equipe.

Em equipes virtuais, os membros estão separados fisicamente (por espaço e/ou tempo) e interagem primariamente por meios eletrônicos, através de redes de computadores e telefones (POLZER, 2004). Exemplos de equipes virtuais são as formadas por pessoas que realizam trabalho interdependente e pelo qual são coletivamente responsáveis, porém trabalham em diferentes regiões geográficas, inclusive em países distintos, como é o caso da equipe objeto deste estudo. Outro exemplo é configurado pelas equipes formadas com o teletrabalho, definido pela Organização Internacional do Trabalho como "uma forma de trabalho efetuada em lugar distante do escritório central e/ou centro de produção que permite a separação física e implica uso de tecnologia facilitadora da comunicação" (BASILE, 2002).

Equipes virtuais se estruturam basicamente da mesma forma que todas as equipes - desde o início caótico até a formação de um conjunto onde a colaboração e a interdependência são desenvolvidas. Quando atingem a maturidade, equipes virtuais alcançam entendimento comum de suas metas e prazos de cumprimento destas, têm 
clara visão da contribuição de todos os membros da equipe, a comunicação entre os membros é fluida e constante, os conflitos são administrados de maneira direta e aberta e os membros sentem-se motivados pelo grupo (HARVEY; DROLET, 1994). Apesar disso, membros de equipes virtuais podem ter pouco, se qualquer, contato pessoal, o que afeta a dinâmica da equipe, principalmente no referente à comunicação e à colaboração entre os membros da mesma.

A seguir, faz-se uma breve análise das tecnologias disponíveis e freqüentemente utilizadas pelas equipes virtuais. O impacto destas tecnologias na comunicação dos membros da equipe é discutido na análise dos resultados desta pesquisa.

\section{TRABALHO COOPERATIVO APOIADO POR COMPUTADOR - CSCW}

Equipes virtuais dependem de tecnologias interativas que possibilitam a comunicação e a transferência de informação entre pessoas dispersas no espaço e no tempo. O termo Computer-Supported Cooperative Work (CSCW), ou trabalho cooperativo apoiado por computador, foi usado pela primeira vez por Irene Greif e Paul Cashman, em 1984, num workshop multidisciplinar organizado para pesquisadores interessados no uso da tecnologia como apoio para a realização de trabalho cooperativo (GRUNDY, 1994).

Alguns autores vêem o conceito de CSCW como sinônimo de groupware (ELLIS, 1991). Segundo Cruz (2002), o conceito de groupware é como um "guardachuva", sob o qual se encontram inúmeras tecnologias que permitem o trabalho em grupo. Outros autores consideram que o CSCW abrange não somente o estudo das técnicas e ferramentas de groupware, mas também os aspectos psicológicos, sociais e organizacionais do seu uso (WILSON, 1991; BRINCK, 1998). Ou seja, groupware define as ferramentas - ou as tecnologias de informação e comunicação - que facilitam a comunicação e a transferência de dados, imagens e/ou sons para o trabalho em grupo dentro dos conceitos de CSCW.

Segundo Wilson (1991), por exemplo, CSCW é um termo bastante genérico, que combina o entendimento de como as pessoas trabalham em grupos utilizando as tecnologias computacionais, incluindo hardware, software, serviços e técnicas. Brinck (1998) define o trabalho cooperativo apoiado por computador, ou CSCW, como toda teoria e/ou prática envolvendo o uso de computadores para melhorar e apoiar as práticas de trabalho em grupo, abrangendo tópicos tão distintos quanto a interação homem-máquina, a sociologia, a psicologia organi- zacional e a interface usuário-software. Esta área de estudo examinaria ainda como o uso da tecnologia afeta as interações em grupo e como a tecnologia pode ser redesenhada para facilitar o trabalho em equipe.

Conforme nota Polzer (2004), as tecnologias mais utilizadas por equipes virtuais envolvem o uso da Internet e de sistemas de videoconferência, fax e telefone (deve-se lembrar que, embora o telefone e o fax possam ser considerados uma classe específica de groupware, o termo normalmente refere-se mais às tecnologias baseadas em networks). A comunicação utilizando estas ferramentas pode ser síncrona ou assíncrona: tecnologias síncronas são aquelas que exigem que os participantes estejam conectados no serviço ao mesmo tempo (exemplos: videoconferências e sistemas de mensagem instantânea); tecnologias assíncronas não requerem que os participantes estejam conectados no mesmo espaço de tempo para que haja comunicação (exemplos: $e$-mail, listas de discussão e newsgroups).

Os subitens a seguir descrevem as diversas ferramentas de groupware, visando um melhor entendimento do "estado-da-arte" na área de CSCW.

\section{Videoconferência}

A videoconferência (sistema interativo de comunicação) permite a transmissão de áudio e vídeo através de rádio, satélite ou linha telefônica e normalmente requer conexão de rede de média e alta velocidade (SILVEIRA, 2002). A Figura 1 ilustra uma sala equipada para videoconferência.

A videoconferência pode ser classificada em multicast ou broadcast. No primeiro caso, o sinal audiovisual é originado e transmitido simultaneamente e em tempo real para todos os locais conectados ao evento, gerando total interatividade e permitindo o diálogo entre os participantes. No segundo caso, o broadcast, o sinal audiovisual é originado em apenas um local e transmitido para vários locais ao mesmo tempo, sem haver interatividade com os participantes. Dependendo do porte, o equipamento de videoconferência pode disponibilizar diversas saídas e entradas auxiliares, permitindo o uso de vários recursos eletrônicos, como: câmara documental, scanner, projetor de slides e de fitas de videocassete, softwares, páginas de Internet, e outros. Em suma, qualquer aparelho que transmita e receba sinais de áudio e vídeo pode ser acoplado ao equipamento de videoconferência.

A videoconferência baseada em computador, com o auxílio das tecnologias de transmissão de voz (VoIP) e imagem (webcam), é uma ferramenta para comunicação em tempo real que se assemelha à videoconferência por redes telefônicas e satélite, e reduz os custos com telefonia. O NetMeeting, por exemplo, desenvolvido pela 
Microsoft, permite videoconferência via Internet, desde que os usuários tenham placa de som e webcam - com este software, pode-se também compartilhar documentos e utilizar quadros de anotações (MOECKEL, 2003).

\section{Internet}

As ferramentas de groupware tendo a Internet como fio condutor são utilizadas individualmente ou combinadas com outras tecnologias e podem tomar várias formas, síncronas e assíncronas. A utilização da Internet facilita a interação entre os membros das equipes virtuais de diversas formas:

\section{E-mail ou correio eletrônico}

E-mail é o mais popular e o mais comum dos aplicativos de groupware (desconsiderando, naturalmente, o telefone). Ainda que a tecnologia básica envolva o envio de mensagens entre duas pessoas, até mesmo os sistemas de $e$-mail mais simples incluem ferramentas para reenviar mensagens, arquivar, criar grupos de $e$ mail e anexar arquivos às mensagens.

Além de possibilitar a troca de mensagens e documentos através de correio eletrônico, pode-se criar um endereço de grupo (listserv) para distribuição de informação e discussão entre os membros da equipe: qualquer questão enviada à lista é redistribuída automaticamente para todos que estejam cadastrados. Os sistemas de $e$ mail permitem o downloading (transferência) de arqui- vos, que é uma ferramenta útil para disponibilizar arquivos aos participantes e receber arquivos destes.

Recentemente, as novas tecnologias em telefonia sem fio estão tornando possível o acesso a contas de $e$-mail sem a necessidade de um computador, através dos telefones celulares. Apesar disso, ainda não há uma forma padrão de acesso e existem algumas questões de compatibilidade com os protocolos de tecnologia sem fio e outras limitações impostas pelo tamanho diminuto dos aparelhos - como o tamanho da tela e o uso do teclado do telefone para o envio de mensagens. Os produtos mais populares que oferecem opções para acesso remoto através de web browsers são o Lotus Notes (da IBM), o Microsoft Exchange (da Microsoft) e o GroupWise, da Novell GroupWise. Dentre estes, o Lotus Notes é o único que pode ser considerado um sistema de groupware, que fornece aos usuários e-mail, workflow, calendários, agenda, listas de tarefas e compartilhamento de documentos. Entretanto, sua infra-estrutura está mais voltada às características assíncronas do groupware, e não às potencialidades da comunicação síncrona.

Também baseadas no serviço de $e$-mail são as listas de discussão e os newsgroups. As listas de discussão facilitam comunicação do tipo broadcast, em que o remetente pode enviar uma mesma mensagem (com ou sem arquivos anexados) para um certo grupo de pessoas (a lista): qualquer pessoa na lista pode enviar sua contribuição e se comunicar com o grupo inteiro. Para a criação e envio de

Figura 1: Sala para videoconferência.

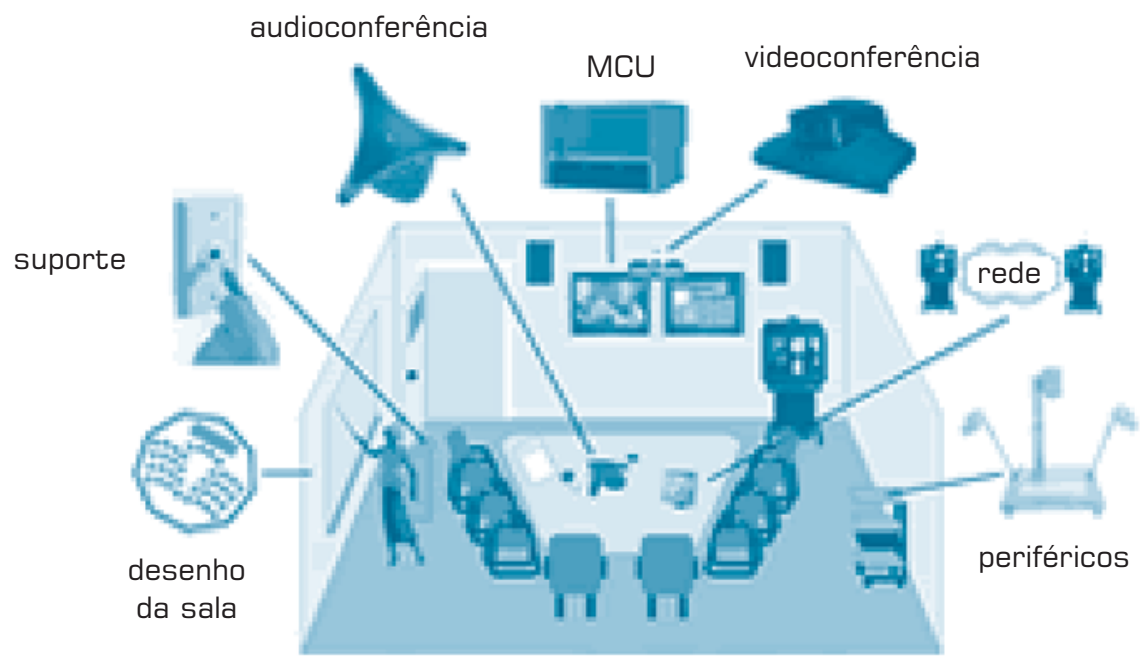

Fonte: http://www. polycom.com. 
mensagens, basta utilizar o correio eletrônico. Na prática, a única diferença entre newsgroups e as listas de discussão é que newsgroups enviam mensagens ao usuário somente quando estas são explicitamente requisitadas - são on demand, ou sob demanda (BRINCK, 1998). Já as listas de discussão enviam mensagens conforme estas são disponibilizadas.

\section{Chat Rooms}

O Chat também é um sistema de mensagens, mas difere do e-mail por ser síncrono - é um sistema de mensagem instantânea, no qual duas ou mais pessoas transmitem e/ou recebem mensagens, gráficos, imagens, som e vídeo. Dentre os vários sistemas temos o ICQ, pioneiro nos sistemas de mensagens instantâneas, o Lotus Instant Messaging Sametime, o AOL e o MSN (MOECKEL, 2003).

\section{Web sites ou páginas web}

Podem ser usadas para manter e distribuir bancos de dados, gráficos, tabelas, organogramas, fluxogramas etc. Os blogs são exemplos de páginas web atualizadas freqüentemente, com possibilidades infinitas de temas e conteúdos.

\section{Intranet sites}

São redes corporativas internas que usam os mesmos protocolos da Internet e facilitam a criação de ambientes virtuais para operação das equipes. Sugestões de uso por equipes virtuais incluem "murais" de metas da equipe, agendas, calendários, e quaisquer outras informações de interesse comum, como listas de telefones e endereços importantes.

\section{Sistemas de workflow}

Como o nome sugere, são sistemas de fluxo de trabalho que permitem que documentos sejam enviados através da organização por um processo relativamente fixo. Um exemplo simples seria um relatório de despesas de viagem: o funcionário preenche o relatório, submete ao sistema e uma cópia é imediatamente arquivada e enviada ao gerente direto para aprovação. Quando o gerente aprova o relatório, este é enviado automaticamente ao departamento contábil para pagamento (BRINCK, 1998). O principal objetivo do workflow é eliminar processos desnecessários e ciclos redundantes, com a finalidade de reduzir tempo de execução e custos.

\section{Calendários de grupo}

Possibilita agendar reuniões e compromissos, gerenciar projetos e coordenar tarefas entre pessoas de um grupo. Ferramentas básicas detectam conflitos de horário e buscam alternativas que possam se encaixar na agenda de todos. Estes calendários ajudam os participantes a localizar uns aos outros e a sincronizar tarefas, desde que todos os participantes mantenham atualizados os seus calendários pessoais.

\section{Quadros de anotações}

Este serviço implementa uma ferramenta através da qual vários usuários compartilham remotamente um "quadro branco", onde podem desenhar, escrever, inserir imagens, fazer anotações etc., interativamente. É uma forma de comunicação síncrona e requer uso de software especial, como o NetMeeting, distribuído gratuitamente com o Internet Explorer (SANTOS; RODRIGUES, 1999).

\section{Sistemas de co-autoria ou editores cooperativos}

São aplicações síncronas que permitem a um grupo compor e editar gráficos ou texto conjuntamente (MOECKEL, 2003). Em uma área de trabalho visualizada por todos os participantes, estes podem acompanhar a atuação dos outros.

\section{Sistemas de apoio à decisão em grupo}

São ferramentas interativas que oferecem auxílio à discussão e tomada de decisões por meio de técnicas específicas. Os modelos incluem ferramentas de votação que possibilitam o cadastro de propostas a serem votadas e ajudam no sistema de votação, contagem dos votos e divulgação de resultados. O objetivo principal é gerar discussão e ajudar na análise do grupo sobre um ou mais projetos, incluindo análises de alternativas (MOECKEL, 2003). Presumivelmente, estes sistemas ajudam a racionalizar o processo decisório.

\section{Mídias}

Entende-se como mídia qualquer recurso digital ou impresso (cartas, CD-ROM, fita de vídeo, DVD e outros) que possa chegar até os usuários. Normalmente, apenas complementam outras tecnologias e não requerem nenhum tipo de equipamento sofisticado para funcionar (SANTOS; RODRIGUES, 1999).

\section{Telefone e fax}

O telefone pode incluir sistema que possibilite a audioconferência (vários participantes) e é considerado a maneira mais rápida e fácil de uma equipe virtual se comunicar verbalmente, devido a sua simplicidade de uso.

As tecnologias citadas proporcionam condições para que se atinja um nível de comunicação entre os participantes que atenda às necessidades do grupo. O uso inadequado dessas tecnologias, entretanto, pode refletir de modo negativo na qualidade total das interações. 


\section{METODOLOGIA}

O estudo de caso que deu origem a este artigo foi desenvolvido através do acompanhamento de um trabalho de implantação de uma empresa de distribuição têxtil, formada nos Estados Unidos por quatro investidores - dois sul-americanos, um asiático e um norteamericano - e com sede administrativa em Miami, Flórida. A equipe de trabalho encarregada da empresa foi composta pelos quatro investidores citados e dois executivos contratados nos Estados Unidos para o desenvolvimento do projeto.

Utilizaram-se como instrumentos para coleta de dados: I) observação participante; II) análise documental de arquivos da empresa; III) questionários aplicados aos seis membros da equipe estudada. A combinação destes diferentes instrumentos de pesquisa, denominada por Triviños (1995) de "técnica da triangulação", objetiva "abranger a máxima amplitude na descrição, explicação e compreensão do foco em estudo".

A coleta dos dados foi realizada em duas etapas: a observação participante e a análise documental se deram ao longo de 20 meses, tempo em que a empresa formada para implantar o centro de distribuição operou em território norte-americano (entre 2001 e 2002). Um dos autores do artigo trabalhou na empresa durante todo este período, o que facilitou a coleta dos dados in loco e o posterior contato com a equipe. Numa segunda etapa, foram aplicados os questionários. Os seis executivos da empresa responderam a um questionário de 12 perguntas fechadas sobre equipes e comunicação virtual. O método utilizado na análise dos resultados é a análise de conteúdo.

Em função do estudo de caso ter sido feito com base em uma experiência fracassada de implementação de uma equipe virtual, os autores mantiveram em sigilo o nome da empresa e os nomes dos executivos envolvidos no projeto.

A pesquisa classifica-se como indutiva em função do método, qualitativa em função do objetivo proposto e como um estudo de caso em função dos procedimentos técnicos adotados.

\section{O CASO DA EMPRESA DE DISTRIBUIC̄ÃO TÊXTIL}

A empresa foi formada para organizar e expandir mundialmente a distribuição de uma marca de roupas. A localização da empresa recém-formada, na cidade de Miami (EUA), era estratégica e alinhada com o objetivo de distribuir a marca para Estados Unidos, Europa, México e alguns países da América Central e do Sul. Como os quatro sócios principais mantinham outros negócios re- lacionados à indústria têxtil em seus países de origem, decidiram contratar dois executivos para ocupar os cargos de CEO - Chief Executive Officer - e CFO - Chief Financial Officer - da nova empresa. A equipe recémformada investiu em campanhas agressivas de publicidade e na rápida expansão da empresa em nível nacional e internacional.

Depois de seis meses em território norte-americano, a empresa havia aberto escritórios e showrooms em Los Angeles e Nova Iorque, contava com 65 funcionários, e mais de 200 clientes nacionais (lojas em shopping centers) e 12 clientes internacionais (distribuidores ou atacadistas) na França, Inglaterra, Espanha, Rússia, Líbano, Canadá, México, Colômbia e alguns países da América Central.

Os quatro sócios, o CEO e o CFO formavam a cúpula diretiva da empresa, e como ocupavam escritórios em regiões dispersas - dois em Miami, um em Nova Iorque, um em Hong-Kong, outro na Venezuela e o último na Argentina - supriram parcialmente a necessidade de locomoção com o uso das tecnologias interativas disponíveis, economizando tempo e dinheiro e agilizando operações.

\section{RESULTADOS}

O questionário aplicado apresenta 12 perguntas fechadas, permitindo respostas do tipo SIM ou NÃO.

Os seis membros da equipe responderam SIM, unanimemente, às seguintes perguntas:

- A equipe utilizou comunicação virtual como principal meio de interação?

- A equipe adotou medidas para compensar as diferenças de horário entre os países envolvidos?

- Você estava treinado para a utilização das tecnologias disponíveis?

- Foram incluídas interações presenciais para discutir prioridades e estabelecer metas e prazos, administrar recursos, e resolver conflitos entre membros?

Os seis membros da equipe responderam NÃO às seguintes perguntas:

- A comunicação entre os membros da equipe foi adequada?

- A equipe estabeleceu protocolos ou regras para uso e envio de material?

- A equipe estabeleceu códigos de conduta quanto ao uso da comunicação eletrônica?

- A equipe estabeleceu uso de um calendário comum ou agenda comum?

A Figura 2, sumariza as respostas nas quais os entrevistados divergiram. 


\section{ANÁLISE E DISCUSSÃO DOS RESULTADOS: O IMPACTO DAS TECNOLOGIAS NA COMUNICAC̣ÃO}

Em termos gerais, os itens apontados na literatura como essenciais em uma equipe estavam presentes no caso estudado: um objetivo comum claro (operar com sucesso um centro mundial de distribuição); aptidões complementares dos membros, cada qual com expertise em diversas áreas; trabalho interdependente que havia sido realizado durante meses para a implementação da empresa e autonomia apontada por Kirkman e Rosen (2000) como sendo diretamente associada ao sucesso das equipes. Nas fases iniciais da empresa, pode-se dizer que os membros formaram não apenas uma equipe virtual, mas uma equipe virtual de alto desempenho que se estruturou rapidamente e colocou um produto novo num mercado bastante competitivo - como é o mercado americano - em apenas seis meses.

Entretanto, a pesquisa aponta para falhas na comunicação que podem ser responsáveis, em parte, pelo fracasso do projeto. Apesar de quatro dos seis membros declararem que a equipe utilizou a comunicação virtual de modo efetivo, todos concordaram que a comunicação, de modo geral, havia sido inadequada, e metade respondeu que o uso de interações presenciais não havia sido suficiente. Uma tentativa de explicação para esta aparente ambigüidade nos resultados pode ser a seguinte: utilizar a comunicação virtual de modo efetivo pode significar saber utilizar os recursos disponíveis, e como todos os participantes estavam treinados no uso destes recursos, eles consideraram que também a comunicação virtual havia sido utilizada de modo efetivo. Isto, no entanto, não quer dizer que a comunicação tenha sido realmente efetiva.
Este resultado parece indicar que a equipe não percebeu as dificuldades específicas da comunicação mediada pelas tecnologias, ou não se deu conta de que, nestas circunstâncias, a comunicação assume nova configuração. Grundy (2000) nota que muitos desentendimentos podem ser facilitados ou intensificados pelo uso das tecnologias na interação entre membros de equipes virtuais. Por exemplo, pode ser difícil encontrar a pessoa com a qual se necessita falar quando numa situação de emergência ou quando um problema necessita de solução imediata. Outra situação, mais comum, ocorre quando os membros da equipe não estão educados para o trabalho em equipes (virtuais ou não) e levam mais tempo que o necessário e desejável para retornar ligações e/ou e-mails. Dificuldades de comunicação podem ocorrer também quando a interpretação de uma mensagem escrita difere da intenção do remetente: é difícil estimar quantas pessoas realmente lêem o que está escrito numa mensagem e respondem adequadamente ao problema proposto pelo remetente.

Ainda que falhas de comunicação ocorram também nas interações presenciais, perceber essas falhas é sem dúvida mais difícil na interação virtual, onde "pistas" comportamentais, como expressões faciais e corporais, tom de voz e estado de ânimo não podem ser avaliadas e usadas para auxiliar no entendimento mútuo. Perceber as diferenças de contexto e estabelecer práticas de trabalho que compensem a falta de interação pessoal - assim como entender os desafios e dinâmicas específicas da comunicação virtual - é o que determina a qualidade da comunicação em geral nas equipes virtuais.

Segundo Grundy (2000), um dos maiores problemas da comunicação virtual é justamente o distanciamento físico, que pode minar a confiança mútua, pois as pessoas tendem

Figura 2: Gráfico das divergências encontradas entre os membros da equipe.

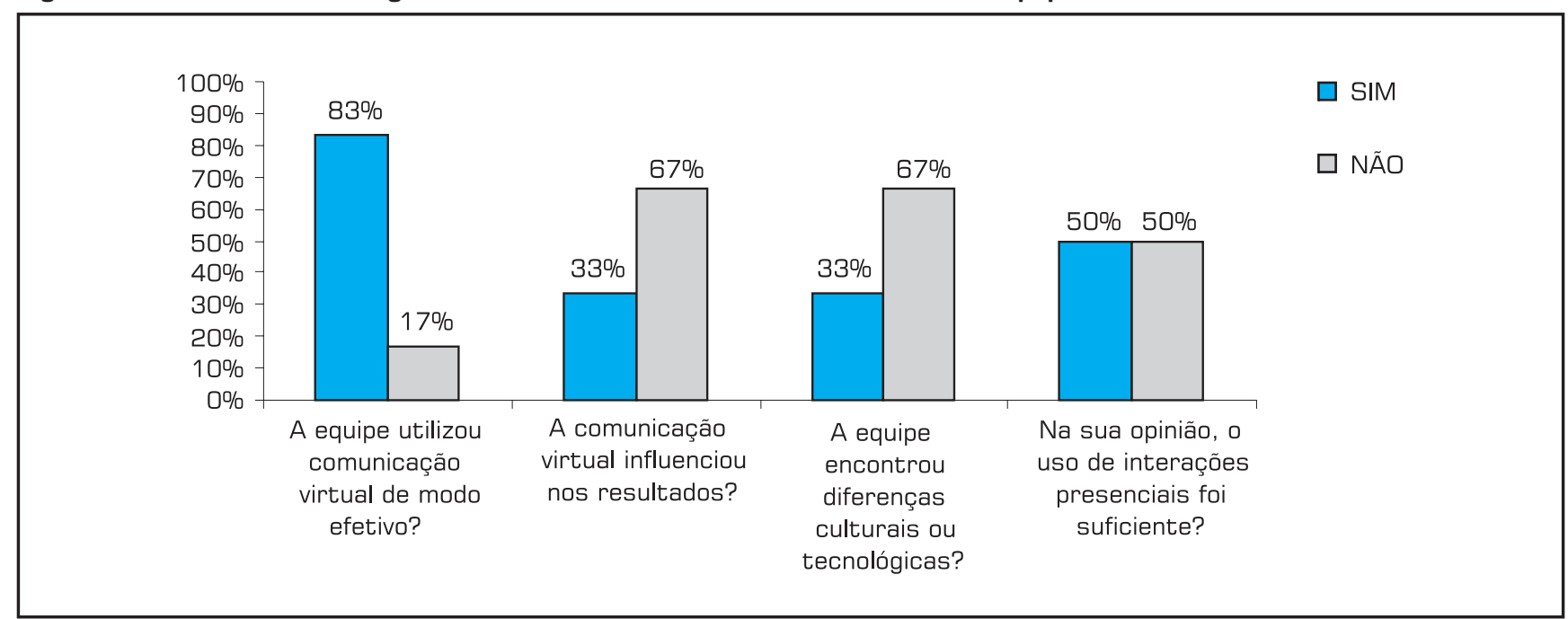


a desconfiar de quem não conhecem ou de quem estão distantes. A proximidade física aumenta também a possibilidade de reconhecimento de valores similares e diminui a possibilidade de mal-entendidos (JARVENPAA, 1998).

Na observação de Jarvenpaa (1998), aspectos sutis, mas importantes, da comunicação presencial, como expressões faciais e corporais que denotam empatia ou agressividade, por exemplo, são mais difíceis de perceber na comunicação virtual (mesmo em sistemas de videoconferência, muito do que se passa do outro lado da câmera é perdido). Nas comunicações via $e$-mail, pequenas ambigüidades podem começar a preponderar, as pessoas podem imaginar o que não foi dito ou, como notado anteriormente, dar uma interpretação à mensagem escrita que seja essencialmente diferente da pretendida pelo remetente: as vantagens perceptivas que possibilitam identificar áreas problemáticas nos relacionamentos estão praticamente ausentes, o que torna este tipo de interação um desafio a ser considerado.

Bing e Laroche (2002) recomendam aos membros de equipes virtuais o exercício de sensibilidade quanto às diferenças de horário e cultura. Uma videoconferência matinal nos EUA é uma conferência noturna na China, e a participação constante de um grupo em horário não conveniente pode gerar ressentimentos - o ideal é variar os horários tentando acomodar o maior número possível de participantes e tendo todos sempre em consideração. Similarmente, é preciso estar atento para diferenças culturais e tecnológicas que possam afetar a comunicação: o uso da tecnologia pode estar mais desenvolvido em uma região geográfica que em outra, e a adoção de uma atitude crítica neste caso pode ofender seriamente um grupo.

De acordo com o questionário, os quatro sócios-proprietários não acreditaram que a diferença de fusos horários ou diferenças culturais ou tecnológicas tivesse afetado o trabalho da equipe - já o CEO e o CFO acreditavam que haviam afetado - provavelmente porque eram os mais envolvidos com a organização de teleconferências e com a distribuição de informação a todos os membros da equipe.

Pode-se verificar pelas respostas ao questionário e pela observação participativa que a equipe estudada poderia haver-se beneficiado de algumas práticas de trabalho sugeridas por Polzer (2004), que compensam a falta de interação pessoal:

- Estabelecimento de códigos de conduta, incluindo prazos máximos para resposta às mensagens eletrônicas e telefonemas. Um problema que esteja circulando por várias mensagens eletrônicas sem resolução provavelmente precisa ser discutido por telefone;

- Uso de um calendário comum, para que todos os membros do time saibam aonde encontrar seus colegas de trabalho, e de uma agenda de trabalho comum, onde os membros possam tomar conhecimento das atividades comuns;
- Sempre que possível, incluir interações presenciais para: discutir prioridades e estabelecer metas e prazos, administrar recursos e resolver conflitos entre membros, já que poder conhecer os membros do time e socializar ajuda a estabelecer relacionamentos e a criar interdependência.

A análise do questionário demonstra que a equipe estudada não havia estabelecido estas práticas de trabalho. Na observação participativa, pôde-se verificar que em várias circunstâncias, especialmente em questões potencialmente conflitantes para os membros da equipe, alguns $e$-mails e telefonemas não eram respondidos em tempo hábil ou eram deliberadamente ignorados. Todos os membros da equipe concordaram que a equipe havia incluído interações presenciais para discutir prioridades e estabelecer metas e prazos, administrar recursos e resolver conflitos entre membros. Porém, metade deles acredita que estas reuniões presenciais não foram suficientes.

Empresas com expertise no uso de equipes virtuais, como a gigante GE, entendem a necessidade de preencher as lacunas possibilitadas pelo distanciamento com reuniões prolongadas aos locais de projeto, telefonemas regulares, e-mails e videoconferências (KANTER; KAO; WIERSEMA, 1998). Das atas de reuniões e análise documental, verifica-se que durante os primeiros seis meses da empresa, os sócios-proprietários reuniram-se presencialmente várias vezes. Quando a empresa estava estabelecida, alguns conflitos de interesse começaram a emergir e os sócios passaram a se reunir presencialmente a cada trimestre, o que aparentava ser insuficiente para a manutenção da equipe e de seus propósitos. De qualquer modo, quatro dos seis entrevistados acreditam que a utilização da comunicação virtual não influenciou nos resultados.

Deve-se destacar ainda que não houve, na empresa estudada, um planejamento e desenho de groupware especial para o desenvolvimento do projeto. O sistema Lotus Notes (IBM), que é uma plataforma de groupware, era utilizado pela empresa têxtil, mas muitas das ferramentas deste sistema não eram compatíveis com o sistema de preferência dos usuários venezuelano e argentino (o Outlook). Os calendários do Lotus, por exemplo, podem ser sincronizados entre os usuários deste sistema, mas não com os calendários de usuários do Outlook. Assim, muitas das ferramentas do Lotus foram subutilizadas ou completamente ignoradas (como os calendários e o workflow). Além disso, o que foi adotado na empresa americana foi adotado por decisão do CEO e do CFO, com algum suporte do sócio de Hong-Kong, mas sem grandes preocupações com compatibilidade ou suporte por parte de todos os usuários. Pode-se afirmar que a preocupação com o desenvolvimento de um sistema de groupware que contasse com o apoio de todos - e que deveria ter sido máxima - 
foi negligenciada. Como nota Tom Brinck (1998), esta preocupação é essencial para o sucesso de um groupware. Segundo este autor, três elementos são básicos no sucesso da implementação:

- Aceitação: sistemas groupware não podem ter sucesso se uma quantidade crítica de usuários não escolher o sistema. O webcam, por exemplo, não tem utilidade alguma se apenas um usuário utilizá-lo;

- Interoperabilidade: no começo dos anos 90, a A\&T e a MCI introduziram comercialmente no mercado os videofones - os dois sistemas, porém, não se comunicavam mutuamente. Esta falta de compatibilidade fez com que muitas empresas que queriam adquirir um sistema esperassem até que um sistema padronizado emergisse;

- Percepção de benefício: mesmo quando todos podem ser beneficiados, se os indivíduos não optarem por utilizar as ferramentas disponíveis o sistema pode falhar. Um exemplo é o sistema de calendários: se todos utilizam o sistema, então todos têm o benefício de poder, com segurança, agendar compromissos baseados nos calendários dos demais. Entretanto, se um ou mais indivíduos percebem esta tarefa como sendo dispensável e pensam que ainda vão usufruir as vantagens de saber do calendário dos outros, o sistema não poderá funcionar.

Morandini (1998) enfatiza que o ideal é que se pratique uma metodologia de desenvolvimento de CSCW com groupware customizado de acordo com as necessidades específicas de cada grupo, e que os usuários participem do projeto juntamente com o projetista. Isto implica no projetista aprender sobre as áreas e sobre a aplicação do futuro projeto, e os usuários aprenderem sobre as novas tecnologias que possam ser utilizadas. Esta prática eliminaria muitos dos riscos de fracassos de softwares projetados para auxiliar grupos, já que normalmente estes fracassos não são devidos a problemas técnicos, mas a fatores sociais e humanos e sua interação com as tecnologias. Morandini (1998) ressalta ainda que, apesar dos benefícios dos groupware, as dificuldades na fase de implementação são maiores que as tipicamente associadas à implementação de software comum: isto porque um sistema de groupware, por melhor que seja, não pode ser bem-sucedido a menos que a maioria ou todo o grupo-alvo esteja disposto a adotar o sistema. Em outras palavras, uma empresa pode ter o melhor sistema de groupware existente, mas a essência do conceito de CSCW, que é o trabalho colaborativo através das tecnologias, só pode ser alcançada com a participação plena das pessoas envolvidas.

Apesar de as tecnologias disponíveis no momento terem sido acessíveis aos participantes desta equipe (e segundo os resultados terem sido adequadas ao nível de colaboração exigida nas tarefas), a comunicação ainda foi comprometida, provavelmente por falta de apoio dos envolvidos ou negligência para com as necessidades de um groupware específico para o grupo em questão.

\section{CONSIDERACÕES FINAIS}

A equipe estudada comunicou-se primariamente via meios eletrônicos e julgou que a comunicação entre os membros da equipe foi inadequada, porém não atribuiu esta inadequação ao uso da comunicação virtual. Como a literatura disponível sobre o tópico aponta para a dificuldade que as equipes virtuais têm para perceber a diferença no contexto, estes resultados não são exatamente ambíguos, mas apenas sugerem que a equipe não fez uma conexão entre o uso da comunicação virtual e as dificuldades com a comunicação total e/ou os resultados.

A equipe adotou medidas para compensar as diferenças de horário entre os países envolvidos, estava treinada na utilização das tecnologias disponíveis e incluiu interações presenciais para discutir prioridades e estabelecer metas e prazos, administrar recursos, e resolver conflitos entre membros. Entretanto, algumas práticas de trabalho que compensam a falta de interação pessoal e influenciam o desempenho das equipes virtuais não foram estabelecidas, e podem haver ocasionado a inadequação na comunicação identificada pela equipe: o não estabelecimento de protocolos ou regras quanto ao uso e envio de material; a falta de um código de conduta para o uso da comunicação eletrônica, e a falta de um calendário ou agenda de trabalho comum. Dois terços da equipe não acreditaram que diferenças culturais ou tecnológicas tivessem afetado o trabalho; ou que a comunicação virtual tivesse influenciado nos resultados da equipe. Metade da equipe, todavia, achou insuficiente o número de reuniões presenciais.

A comunicação virtual possui algumas peculiaridades que devem ser levadas em consideração para o ótimo desempenho das equipes. Equipes virtuais efetivas reconhecem as dificuldades extras geradas pela interação virtual, e desenvolvem práticas de trabalho que compensam a falta de interação pessoal.

Além de cometer erros operacionais que foge ao objetivo deste trabalho analisar, a equipe estudada não empenhou esforços no sentido de desenvolver um groupware customizado (que pudesse se enquadrar nas necessidades da equipe) e não conseguiu superar alguns dos obstáculos comuns às equipes virtuais, o que pode haver contribuído para o insucesso do projeto. Os problemas na comunicação, exacerbados por falhas no uso da comunicação virtual, ficaram evidentes na pesquisa, em novembro de 2002, apenas 1 ano e 8 meses depois de haver-se instalado nos EUA, a empresa fechou o escritório de Miami, encerrando o projeto de distribuição mundial. 
Artigo recebido em 11/07/2005

Aprovado para publicação em 03/11/2005

\section{- Referências Bibliográficas}

BASILE, S. Teletrabalho. In: BOOG, G.; BOOG, M. (coord.) Manual de gestão de pessoas e equipes, v. 2. São Paulo: Gente, 2002. p. 675-688.

BING, C. M.; LAROCHE, L. Communication technologies for virtual teams. OD Practitioner, South Orange, NJ, v. 34, n. 2, 2002.

BRINCK, T. Groupware. Usability First. Disponível em: <http://www. usabilityfirst.com/groupware/ intro.txl > Acesso em: 28 out. 2005.

CRUZ, T. Workflow: a tecnologia que vai revolucionar os processos. 2. ed. São Paulo: Atlas, 2002.

DRUCKER, P. F. Administrando em tempos de grandes mudanças. São Paulo: Pioneira Thomsom Learning, 2001.

ELLIS, C. A.; GIBBS, S. J.; REIN, G. L. Groupware: some issues and experiences. Communications of the $A C M$, v. 34 , n. 1, p. 38-59, 1991.
GRUNDY, J. Computer-supported cooperative work: Its history and participation. IEEE Computer, v. 27, n. 5, p. 19-26, 1994.

Trust in virtual teams: a knowledge ability white paper. Knowledge Ability. Disponível em: $<$ http://www.knowab.co.uk/ wbwtrust.pdf $>$ Acesso em: 05 mar. 2005.

HARVEY, T. R; DROLET, B. Building teams, building people. La Verne, California: Technomic, 1994.

JARVENPAA, S. L. Communication and trust in virtual teams. Journal of Computer Mediated Communication, v. 4, n. 3, 1998. Disponível em: <http:/ /www.ascusc.org/jcmc/> Acesso em: 06 mar. 2005.

KANTER, R. M.; KAO, J.; WIERSEMA, F. Inovação: pensamento inovador na 3M, DuPont, GE, Pfizer Rubbermaid. São Paulo: Negócio, 1998.
KATZENBACH, J. R.; SMITH, D. K Equipes de alta performance: conceitos princípios e técnicas para potencializar o desempenho das equipes. Rio de Janeiro: Campus, 2001

KEY ENTERPRISE SOLUTIONS, Note vs. exchange. Disponível em: <http:// www.keysolutions.com/ > Acesso em: 28 out. 2005.

KIRKMAN, B. L.; ROSEN, B. Powering up teams. Organizational dynamics, v. 28 , n. 3 , p. $48-65$, winter 2000

MOECKEL, A. CSCW: conceitos e aplicações para cooperação. Curitiba: CEFET-PR, 2003. 35 p.

MORANDINI, M. Critérios e requisitos para avaliação da usabilidade de interfaces em groupware - CSCW. Faculdade de Engenharia Elétrica e de Computação - FEEC. UNICAMP. Campinas, 1998. Disponível em: <http:// www.dca.fee.unicamp.br/courses/ IA368F/1s 1998/Monografias/ morandini.html $>$ Acesso em: 28 out 2005.
MOSCOVICI, F. Equipes dão certo. Rio de Janeiro: José Olympio, 1998.

POLYCOM. Disponível em: <http:// www.polycom.com/home/> Acesso em: 24 set. 2004

POLZER, J. T. Creating teams with an edge. Boston: Harvard Business School Press, 2004

SANTOS, E.; RODRIGUES, M. Educação à distância: conceitos, tecnologias, constatacões, presunções e recomendações. São Paulo: EDUSP, 1999.

SILVEIRA, R. D. da. Videoconferência: educação sem distância. Curitiba: Universidade Eletrônica do Brasil, 2002.

TRIVIÑOS, A. N. S. Introdução à pesquisa em Ciências Sociais: a pesquisa qualitativa em educação. São Paulo: Atlas, 1995.

WILSON, P. Computer supported cooperative work: an introduction. Oxford: Intellect, 1991.

\section{- Sobre os autores}

Viviane Carvalho Bejarano

Mestranda em Engenharia de Produção - Universidade Tecnológica Federal do Paraná - Campus Ponta Grossa

Telefone: (41) 3343-7715 E-mail: vivbe@ hotmail.com

Prof. Dr. Luiz Alberto Pilatti

Professor do Programa de Mestrado em Engenharia de Produção - Universidade Tecnológica Federal do Paraná Campus Ponta Grossa

Telefone: (42) 3220-4801_E-mail: lapilatti@pg.cefetpr.br

\section{Prof. Dr. Luciano Scandelari}

Professor do Programa de Mestrado em Engenharia de Produção - Universidade Tecnológica Federal do Paraná Campus Ponta Grossa

Telefone: (42) 3220-4805_E-mail: luciano@ cefetpr.br

\section{Antonella Carvalho de Oliveira}

Mestranda em Engenharia de Produção - Universidade Tecnológica Federal do Paraná - Campus Ponta Grossa

Telefone: (41) 3261-2415Ｅ-mail: antonellacarvalho@terra.com.br

Endereço: UTFPR - Campus Ponta Grossa

Programa de Pós-Graduação em Engenharia de Produção - PPGEP

Avenida Monteiro Lobato, km 04, s/n. - Caixa Postal, 20 - CEP 84016-210 - Ponta Grossa - Paraná

Phone/Fax: (042) 3220-4805 